\title{
Habits model of elderly with diabetes mellitus in the coastal area of Madura Indonesia
}

\author{
Eko Mulyadi * (D), Mujib Hannan ${ }^{1}$ D, Anik Anekawati ${ }^{2}$ D, Bambang Widjanarko Otok $^{3}$ (D) \\ ${ }^{1}$ Department of Nursing, Faculty of Health Science, Universitas Wiraraja, Sumenep, Indonesia; ${ }^{2}$ Department of Science \\ Education, Faculty of Teacher Training and Education, Universitas Wiraraja, Sumenep, Indonesia; ${ }^{3}$ Department of Statistics, \\ Institut Teknologi Sepuluh Nopember, Surabaya, Indonesia
}

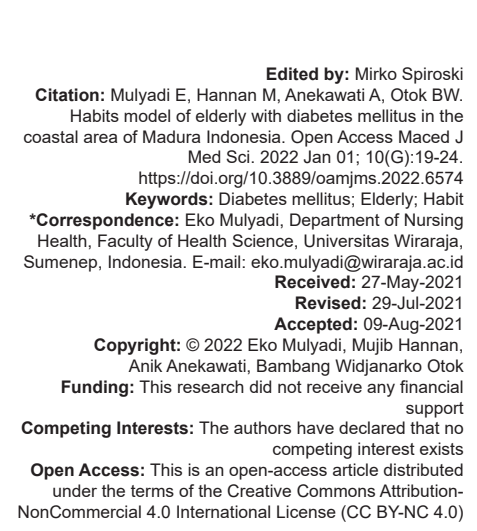

\section{Introduction}

The development of research on diabetes mellitus (DM) increases every year. The highest number of DM studies was in 2015 with 75,206 studies and $90 \%$ were cited. This shows that the world's attention to DM is quite large and increasing. In Indonesia, DM has increased more than infectious diseases, in Madura, $\mathrm{DM}$ is also increasing, even though the Madurese are known to dislike sweet foods. This may occur because wrong eating habits, lifestyle, and stress levels can affect blood sugar levels in the body [1], [2], [3].

Depression is always found in one out of every four people with type 2 diabetes. Depression also increases the risk of diabetes, hyperglycemia, insulin resistance, and other micro and macrovascular complications. Conversely, a diagnosis of type 2 DM also increases the risk of incidence of depression and may contribute to more severe depression. This linkage reflects a shared etiology consisting of a complex twoway interaction between many variables. It includes autonomic and neurohormonal dysregulation, weight gain, inflammation, and hippocampal structural changes. Two recent meta-analyses of trials of randomized controlled depression treatment in patients with type 2 DM concluded that psychotherapy and antidepressant drugs, respectively, are quite effective for depression and cognitive behavioral therapy (CBT) has a beneficial effect on glycemic control [4], [5], [6].

Another study states that the comorbidity of depression and DM is risk factors for cognitive decline in the elderly in Mexico America. Interventions that reduce the prevalence of depression and DM in Mexican Americans can reduce the number of adults experiencing a cognitive decline [7], [8].

On the other hand, there are currently no strategies to prevent or delay other disorders such as cognitive impairment [9]. The purpose of this study is how to model daily life patterns in elderly people with diabetes in the coastal area of Madura. This modeling uses structural equation modeling analysis with smartPLS software. This research is the basis for creating a model for overcoming the impact of DM and improving the quality of life for elderly people with DM. The benefits of this research are to improve the quality of life of people with diabetes, especially the elderly, 
and indirectly have an impact on the Indonesian economy.

\section{Methods}

This study used an analytical design to model the living habits of the elderly with DM on the coast of Madura, the study population of the Madura coastal elderly community with DM, with 47 elderly DM as sample using purposive sampling technique, There are two exogenous latent variables, two endogenous latent variables, and one endogenous manifest variable. The first exogenous latent variable is the characteristic of the respondent which has four indicators: Gender, occupation, education, and age. The second exogenous latent variable is the coping mechanism which has 3 indicators: primary, secondary, and tertiary. The first endogenous latent variable is activity daily life (ADL) which has nine indicators: Bowel performance, Bladder performance, Grooming performance, Toilet use performance, Mobility performance, Feeding performance, Transfer performance, Stairs performance, and Dressing performance. The second endogenous latent variable is a psychiatric condition that has three indicators, namely: Anxiety, depression, and stress. The endogenous manifest variable is blood sugar levels.

The instruments used were the Barthel index questionnaire to assess ADL, the Depression Anxiety Stress Scale questionnaire, and the respondent characteristic questionnaire. The results of the study were analyzed using structural equation modeling analysis with smart-PLS software.

\section{Results}

\section{Evaluation of the outer model}

\section{Convergent validity}

Several references state that a factor loading of 0.50 is considered to have sufficiently strong validation to explain latent constructs [10]. Table 1 is a summary of the loading value of the output. The latent variable of respondent characteristics has only one valid indicator, namely age. The latent variable of coping mechanism is only one invalid indicator, namely secondary (a person's self-defense mechanism consisting of Emotional Focusing Engagement, Emotional Focusing Disengagement, and Problem Focusing). The latent variable of daily life activity has nine indicators, only two indicators are invalid, namely, ADL3 (ability to dress up) and ADL6 (ability to walk). Meanwhile, the latent variable of psychiatric conditions is only one invalid indicator, namely, anxiety (excessive anxiety/tension).

Table 1: Loading factor value

\begin{tabular}{lll}
\hline Variable latent & Indicator & Factor loading \\
\hline Respondent & Sex (KR1) & 0.171 \\
characteristic & age (KR2) & 0.935 \\
& Job (KR3) & -0.542 \\
Coping mechanism & Education (KR4) & -0.573 \\
& Primer (MK1) & 0.555 \\
Activity Daily Life & Secondary (MK2) & -0.290 \\
& Tertiary (MK3) & 0.746 \\
& ADL1 & 0.889 \\
& ADL2 & 0.639 \\
& ADL3 & 0.422 \\
& ADL4 & 0.841 \\
& ADL5 & 0.647 \\
& ADL6 & 0.222 \\
Psychiatric condition & ADL7 & 0.749 \\
& ADL8 & 0.740 \\
& ADL9 & 0.748 \\
& Depression (KJ1) & 0.878 \\
& Anxiety (KJ2) & 0.247 \\
& Stress (KJ3) & 0.910 \\
\hline
\end{tabular}

\section{Discriminant validity}

The following is the cross-loading value of each indicator. Table 2 shows that the correlation of the latent variable of the respondent's characteristics with its indicators is greater than the indicators of the other three latent variables. This shows that the latent variable of respondent characteristics predicts indicators in their group better than indicators from other groups and it can be concluded that the latent variable of respondent characteristics has good discriminant validity.

Table 2: Cross loading value

\begin{tabular}{|c|c|c|c|c|}
\hline Indicator & $\begin{array}{l}\text { Respondent } \\
\text { characteristic }\end{array}$ & $\begin{array}{l}\text { Activity } \\
\text { daily life }\end{array}$ & $\begin{array}{l}\text { Psychiatric } \\
\text { condition }\end{array}$ & $\begin{array}{l}\text { Coping } \\
\text { mechanism }\end{array}$ \\
\hline $\begin{array}{l}\text { ADL1 Bowel } \\
\text { performance }\end{array}$ & -0.711 & 0.889 & 0.079 & -0.068 \\
\hline $\begin{array}{l}\text { ADL2 Bladder } \\
\text { performance }\end{array}$ & -0.637 & 0.639 & 0.132 & -0.087 \\
\hline $\begin{array}{l}\text { ADL3Grooming } \\
\text { performance }\end{array}$ & -0.262 & 0.422 & 0.068 & 0.112 \\
\hline $\begin{array}{l}\text { ADL } 4 \text { Toilet use } \\
\text { performance }\end{array}$ & -0.613 & 0.841 & 0.020 & -0.155 \\
\hline $\begin{array}{l}\text { ADL5 Feeding } \\
\text { performance }\end{array}$ & -0.325 & 0.647 & -0.160 & 0.000 \\
\hline $\begin{array}{l}\text { ADL6 Mobility } \\
\text { performance }\end{array}$ & -0.199 & 0.222 & -0.173 & 0.080 \\
\hline $\begin{array}{l}\text { ADL7 Transfer } \\
\text { performance }\end{array}$ & -0.364 & 0.749 & -0.197 & -0.025 \\
\hline $\begin{array}{l}\text { ADL8 Dressing } \\
\text { performance }\end{array}$ & -0.383 & 0.740 & 0.030 & -0.088 \\
\hline $\begin{array}{l}\text { ADL9 Stairs } \\
\text { performance }\end{array}$ & -0.662 & 0.748 & 0.227 & -0.129 \\
\hline Depression (KJ1) & -0.295 & 0.044 & 0.878 & -0.323 \\
\hline Anxiety (KJ2) & 0.038 & -0.059 & 0.247 & -0.004 \\
\hline Stress (KJ3) & -0.308 & 0.072 & 0.910 & -0.397 \\
\hline Sex (KR1) & 0.171 & 0.000 & -0.203 & 0.082 \\
\hline Age (KR2) & 0.935 & -0.803 & -0.219 & 0.248 \\
\hline Job (KR3) & -0.542 & 0.256 & 0.197 & -0.028 \\
\hline Education KR4) & -0.573 & 0.230 & 0.469 & -0.223 \\
\hline $\begin{array}{l}\text { Primer coping } \\
\text { mechanism (MK1) }\end{array}$ & 0.123 & 0.006 & -0.179 & 0.555 \\
\hline $\begin{array}{l}\text { Secondary coping } \\
\text { mechanism MK2) }\end{array}$ & -0.175 & 0.049 & 0.167 & -0.290 \\
\hline $\begin{array}{l}\text { Tertiary coping } \\
\text { mechanism (MK3) }\end{array}$ & 0.141 & -0.094 & -0.292 & 0.746 \\
\hline
\end{tabular}

The correlation of the coping mechanism latent variable with its indicators is greater than the indicators of the other three latent variables. This shows that the coping mechanism latent variable predicts the indicators in his group better than the indicators from other groups and it can be concluded that the coping mechanism latent variables have good discriminant validity. 
The correlation of the latent variable of daily life activity with its indicators is greater than the indicators of the other three latent variables. This shows that the latent variable of daily life activity predicts indicators in his group better than indicators from other groups and it can be concluded that the latent variable of daily life activity has a good validity discriminant.

The correlation of the psychiatric condition latent variable with its indicators is greater than the indicators of the other three latent variables. This shows that the latent variable of psychiatric conditions predicts indicators in his group better than indicators from other groups and it can be concluded that the latent variables of psychiatric conditions have good discriminant validity. All values AVE of the four latent variables are more than the correlation values between latent variables (Table 3 ). This shows that all latent variables have good discriminant validity.

Table 3: AVE value and correlation

\begin{tabular}{|c|c|c|c|c|c|c|}
\hline \multirow[t]{2}{*}{ Variable latent } & \multirow[t]{2}{*}{ AVE } & \multirow[t]{2}{*}{ AVE } & \multicolumn{4}{|l|}{ Correlation } \\
\hline & & & $\begin{array}{l}\text { Respondent } \\
\text { characteristic }\end{array}$ & $\begin{array}{c}\text { Coping } \\
\text { mechanism }\end{array}$ & $\begin{array}{c}\text { Activity } \\
\text { Daily Life }\end{array}$ & $\begin{array}{l}\text { Psychiatric } \\
\text { condition }\end{array}$ \\
\hline $\begin{array}{l}\text { Respondent } \\
\text { characteristic }\end{array}$ & 0.381 & 0.617 & 1 & 0.253 & -0.748 & -0.327 \\
\hline Coping mechanism & 0.316 & 0.562 & 0.253 & 1 & -0.095 & -0.397 \\
\hline Activity & 0.469 & 0.685 & -0.748 & -0.095 & 1 & 0.060 \\
\hline Daily Life & & & & & & \\
\hline $\begin{array}{l}\text { Psychiatric } \\
\text { condition }\end{array}$ & 0.553 & 0.744 & -0.327 & -0.397 & 0.060 & 1 \\
\hline
\end{tabular}

\section{Reliability}

Reliability testing is carried out to prove the accuracy, consistency, and accuracy of the instrument in measuring constructs or latent variables. In this study, the reliability test used the composite reliability value and Cronbach's alpha. In general, composite reliability and Cronbach's alpha of more than 0.6 are acceptable [11]. The composite value is reliable and Cronbach's alpha for confirmatory studies is more than 0.7 , while for explanatory studies more than 0.6 is still acceptable [12], [13], [14]. The following table is a summary of the composite reliable values and Cronbach's alpha of the latent variables.

Table 4 shows that the composite value is reliable and Cronbach's alpha for the latent variable ADL and psychiatric conditions more than 0.7 . These results can be concluded that the latent variables of daily life activity and mental conditions are reliable or the indicators of these variables are consistent in measuring daily life activity and psychological conditions. Meanwhile, the latent variable of respondent characteristics and coping mechanism has a reliable composite value of less than 0.6 . This shows that the two latent variables have poor reliability.

\section{Test the significance of the outer model}

Table 4: Composite reliable and Cronbach's Alpha value

\begin{tabular}{lll}
\hline Variable latent & Composite reliability & Cronbach's Alpha \\
\hline Respondent Characteristic & 0.000 & -3829 \\
Coping Mechanism & 0.333 & 0.248 \\
Activity Daily Life & 0.879 & 0.845 \\
Psychiatric condition & 0.756 & 0.568 \\
\hline
\end{tabular}

The PLS-SEM method cannot be tested for the significance of the model, because the data distribution is unknown. Therefore, the significance test uses the resampling bootstrapping method. The following is a summary of the significance test results for both the outer model using $\alpha=5 \%$.

Two significant indicators are not statistically valid on the latent variable of the respondent's characteristics, namely gender and education. There is one significant indicator that is not statistically valid on the latent variable of daily life activity, namely, ADL6 (ability to walk). There is one indicator in the latent variable of the coping mechanism which is statistically significant, namely, the coping mechanism. There is a significant indicator that is not statistically valid on the latent variable of psychiatric conditions, namely, anxiety.

Table 5 shows that the latent variables of respondents' characteristics are formed by 4 indicators, where the results of the outer model test show valid age and job indicators. That is, in this model, age and job are indicators that can build the respondent's characteristic construct. The latent variable of daily life activity is formed by 9 indicators, where the results of the outer model test show that only the transfer performance indicator is invalid. That is, in this model, all indicators except transfer performance are indicators that can build latent constructs of activity daily life.

The latent variable of the coping mechanism is formed by 3 indicators, where the results of the outer model test show that only tertiary indicators are valid. That is, in this model, only tertiary indicators can build latent constructs of coping mechanisms.

The latent variable of the psychological condition is formed by 3 indicators, where the outer model test results show that only the anxiety indicator is invalid. That is, in this model, the construct of mental conditions is built on depression and stress.

Table 5: The result of outer model significance test

\begin{tabular}{|c|c|c|c|}
\hline Indicator & t-stat & $\mathrm{p}$-value & Interpretation \\
\hline Sex $($ KR1) $\leftarrow$ Respondent characteristic & 0.475 & 0.635 & Not valid \\
\hline Age (KR2) $\leftarrow$ Respondent characteristic & 5.202 & 0.000 & Valid \\
\hline Education $(K R 3) \leftarrow$ Respondent characteristic & 1.723 & 0.086 & Not Valid \\
\hline Job $(K R 4) \leftarrow$ Respondent characteristic & 2.485 & 0.013 & Valid \\
\hline ADL 1 Bowel performance $\leftarrow$ Activity Daily Life & 3.098 & 0.002 & Valid \\
\hline ADL 2 Bowel performance $\leftarrow$ Activity Daily Life & 2.949 & 0.003 & Valid \\
\hline ADL 3 Grooming performance $\leftarrow$ Activity Daily Life & 2.071 & 0.039 & Valid \\
\hline ADL 4 Toilet use performance $\leftarrow$ Activity Daily Life & 3.126 & 0.002 & Valid \\
\hline ADL 5 Feeding performance $\leftarrow$ Activity Daily Life & 2.730 & 0.007 & Valid \\
\hline ADL 6 Mobility performance $\leftarrow$ Activity Daily Life & 0.908 & 0.365 & Not valid \\
\hline ADL 7 Transfer performance $\leftarrow$ Activity Daily Life & 2.964 & 0.003 & Valid \\
\hline ADL 8 Dressing performance $\leftarrow$ Activity Daily Life & 3.158 & 0.002 & Valid \\
\hline ADL 9 Stairs performance $\leftarrow$ Activity Daily Life & 2.916 & 0.004 & Valid \\
\hline Primer $($ MK1) $\leftarrow$ Mekanisme Koping & 1.367 & 0.172 & Not valid \\
\hline Secondary (MK2) $\leftarrow$ coping mechanism & 0.563 & 0.573 & Not valid \\
\hline Tertiary (MK3) $\leftarrow$ coping mechanism & 1.991 & 0.047 & Valid \\
\hline Depresion (KJ1) $\leftarrow$ Psychiatric condition & 2.730 & 0.007 & Valid \\
\hline Anxiety (KJ2) $\leftarrow$ Psychiatric condition & 0.624 & 0.533 & Not valid \\
\hline Stress $(\mathrm{KJ} 3) \leftarrow$ Psychiatric condition & 2.683 & 0.008 & Valid \\
\hline
\end{tabular}

\section{Inner model evaluation}

Testing of the inner model is done by looking at the results of the significance test of the effect of exogenous latent variables on endogenous latent 
variables or endogenous latent variables on other endogenous latent variables. The significance test in PLSSEM uses the resampling bootstrapping method because of the unknown data distribution. The results of the model significance test are shown in Table 6 as follows.

Table 6: Significance test of inner model and p-value

\begin{tabular}{llll}
\hline Relationship & t-stat & p-value & Interpretation \\
\hline Activity Daily Life $\rightarrow$ blood glucose level & 0.103 & 0.918 & Not Significant correlation \\
Respondent characteristic $\rightarrow$ Activity Daily Life & 2.712 & 0.007 & Significant correlation \\
Psychiatric condition $\rightarrow$ blood glucose level & 1.187 & 0.236 & Not Significant correlation \\
Coping mechanism $\rightarrow$ Psychiatric condition & 2.239 & 0.026 & Significant correlation \\
\hline
\end{tabular}

Table 6 shows that there is only the effect of Respondent Characteristics on ADL and Coping Mechanisms on Psychiatric Conditions. Significance test results in Table 6 . It shows that there is an influence of respondent characteristics on ADL with a coefficient of -0.748 and an R-square value of 0.559 in the moderate category [14]. This shows that the variability of the latent variable of ADL can be explained by the variability of the respondent's characteristics of $55.9 \%$, and the remaining $44.1 \%$ is explained by other variables outside the characteristics of the respondent.

Significance test results in Table 6. It shows that there is an influence of the coping mechanism on the psychological condition with a coefficient of -0.397 and an R-square value of 0.158 in the weak category [14]. This shows that the variability of the latent variable of psychiatric conditions can be explained by the variability of the coping mechanism of $15.8 \%$, the remaining $84.2 \%$ is explained by other variables outside the coping mechanism.

The following is a summary of the size of the indirect, direct, and total influence of exogenous latent variables to endogenous latent variables or from endogenous latent variables to other endogenous latent variables as shown inTable 7.

Table 7: Direct, indirect, and total correlation

\begin{tabular}{llll}
\hline Variable latent & Activity daily life & psychiatric Condition & Blood glucose level \\
\hline Respondent characteristic & -0.748 & & -0.012 \\
Coping mechanism & & -0.397 & -0.073 \\
Activity Daily Life & & & 0.016 \\
Psychiatric condition & & 0.185 \\
\hline
\end{tabular}

Figure 1 below shows the model and the coefficient value of the relationship between indicators and their constructs and between latent variables and other variables.

The R-square value is a measure of the goodness-fit of a model. According to Chin (1998), the R-square values of $0.67,0.33$, and 0.19 indicate that the model is strong, moderate, and weak, respectively [13]. Meanwhile, according to Hair et al. (2009), the R-square value is $0.75,0.50$, and 0.25 indicate the strong, moderate, and weak models, respectively [14]. The following Table 8 shows the R-square value.

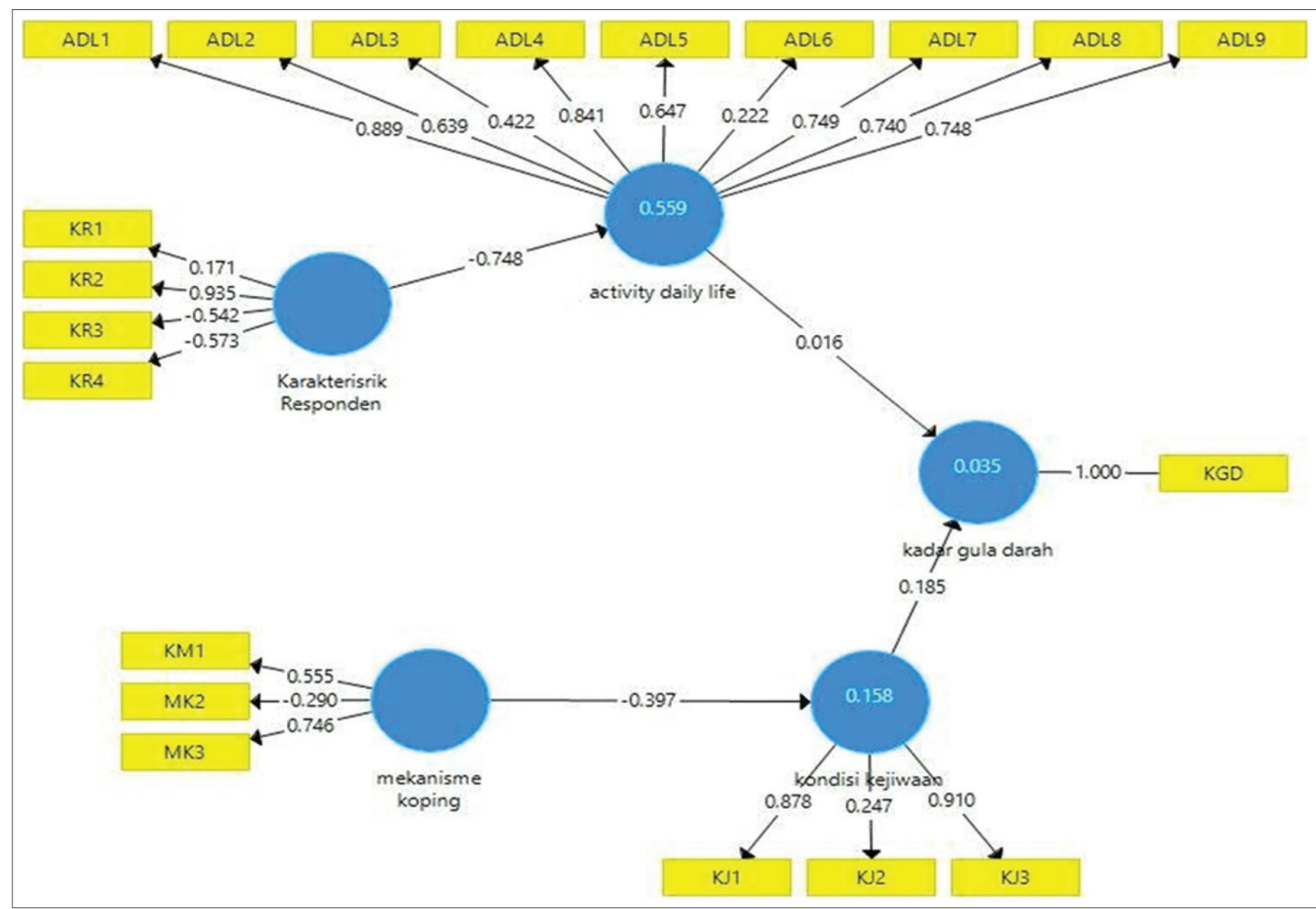

Figure 1: The model with coefficient value 
Table 8: $\mathbf{R}$-square value in the full model

\begin{tabular}{lll}
\hline Variable & R-square & Interpretation \\
\hline Activity daily life & 0.559 & Model moderate \\
Blood glucose level & 0.035 & Model weak \\
Psychiatric conditions & 0.158 & Model weak \\
\hline
\end{tabular}

Significance test results show that there is an influence of respondent characteristics on ADL with a coefficient of -0.748 and an R-square value of 0.559 in the moderate category. This suggests that the latent variable of Daily Life Activity variability can be explained by the characteristics of respondents at $55.9 \%$, the remaining $44.1 \%$ is explained by other outside variables. There is an influence of the coping mechanism on the psychological condition with a coefficient of -0.397 and an R-square value of 0.158 in the weak category. This shows that the latent variable of psychiatric conditions can be explained by coping mechanism of $15.8 \%$, the remaining $84.2 \%$ is explained by other variables outside the coping mechanism.

\section{Discussion}

The model analysis shows that daily activities of the elderly do not have a significant effect on blood sugar levels, because the daily activities of the elderly are low intensity, such as dressing, eating, walking, and toileting. A study shows when matched for total period, moderate-intensity endurance-type exercise shows a more effective strategy to manage daily blood glucose homeostasis than repeated bouts of $A D L$. Nevertheless, the introduction of repeated bouts of ADL during prolonged sedentary behavior forms a valuable strategy to manage postprandial glucose handling in patients with type 2 diabetes [15]. Not only can it control blood sugar levels, but also may be able to control the blood pressure of DM patients [16].

The model analysis shows that respondent characteristic have a significant effect to ADL. It similar with the research that daily activities may be influenced by the characteristics of a person, such as gender, occupation, and age. How do usually older adults spend their day? In ancient times before the internet, there are three activity categories usually older adults spend their day: obligatory activities (personal selfmaintenance and IADLs), leisure (reading, television viewing, or other activities), or resting [17]. At the time internet becoming familiar, elderly adapting, and a study shows male elders seem to perceive more usefulness due to higher levels of ease of use than woman. This ease of use is also better explained by the level of enjoyment for males [18]. Finally, now internet is found to influence five dimensions of elderly consumers' wellbeing: enjoyment, personal growth, mastery, autonomy, and social connectedness [19].
The model analysis shows that there is no relationship between psychological conditions and blood sugar levels. Contradicted with the previous research has shown that psychological conditions such as stress can affect blood sugar levels [20], and vice versa, blood sugar levels affect psychological conditions [21]. This may be because there are other variable that affect blood glucose levels, such as diet. Well known that diet management was a primary intervention for diabetes, present research also support dietary therapy was effective to improve blood glucose profile [22].

The model analysis shows that coping mechanism has a significant effect on psychiatric condition, this is consistent with other studies reported, Maladaptive coping strategies of venting and self-blame, behavioral disengagement, were significantly associated with higher perceived stress scores and the new addition of an exercise coping mechanism significantly associated with the lower perceived stress scores. Use of prescribed medications was not significantly associated with perceived stress levels [23].

\section{Conclusion}

Model analysis shows that only two significant variable: First, respondent characteristics to ADL and second, coping mechanism to psychiatric conditions, while other variables are not significant. This may be due to the existence of other variables such as diet and others that were not studied.

\section{References}

1. Rondhianto $\mathrm{K}$, Melaniani $\mathrm{S}$. The effect of diabetes selfmanagement education, based on the health belief model, on the psychosocial outcome of Type 2 diabetic patients in Indonesia. Indian J Public Health Res Dev. 2018;9(11):1718-23. https://doi.org/10.5958/0976-5506.2018.01691.1

2. Dewi ER, Prasetyo B, Laksana MA, Joewono HT, Wittiartika ID. The early detection in gestational diabetes mellitus at Indonesia primary health care. Indian J Forensic Med Toxicol. 2020;14(2):1552-6.

3. Arifin $B$, Idrus LR, van Asselt AD, Purba FD, Perwitasari DA, Thobari JA, et al. Health-related quality of life in Indonesian Type 2 diabetes mellitus outpatients measured with the Bahasa version of EQ-5D. Qual Life Res. 2019;28(5):1179-90. https:// doi.org/10.1007/s11136-019-02105-z PMid:30649698

4. Semenkovich K, Brown ME, Svrakic DM, Lustman PJ. Depression in Type 2 diabetes mellitus: Prevalence, impact, and treatment. Drugs. 2015;75(6):577-87. https://doi.org/10.1007/ s40265-015-0347-4 


\section{PMid:25851098}

5. Estuningsih Y, Rochmah TN, Andriani M, Mahmudiono T. Effect of self-regulated learning for improving dietary management and quality of life in patients with Type-2 diabetes mellitus at Dr. Ramelan Naval Hospital, Surabaya, Indonesia. Kesmas. 2019;14(2):51-7. https://doi.org/10.21109/kesmas.v14i1.2257

6. Samudera WS, Efendi F, Indarwati R. Effect of community and peer support based healthy lifestyle program (CP-HELP) on self care behavior and fasting blood glucose in patient with Type 2 diabetes mellitus. J Diabetes Metab Disord. 2021;20(1):729. https://doi.org/10.1007/s40200-021-00729-y

7. Downer B, Vickers BN, AI Snih S, Raji M, Markides KS. Effects of comorbid depression and diabetes mellitus on cognitive decline in older Mexican Americans. J Am Geriatr Soc. 2016;64(1):10917. https://doi.org/10.1111/jgs.13883 PMid:26782859

8. Anam WA, Massaid A, Amesya NA, Chamidah N. Modeling of Diabetes Mellitus Risk Based on Consumption of Salt, Sugar, and Fat Factors Using Local Linear Estimator. Vol. 2264. In: AIP Conference Proceedings; 2020. https://doi. org/10.1063/5.0023498

9. Sastre AA, Vernooij RW, Harmand MG, Martínez G. Effect of the treatment of Type 2 diabetes mellitus on the development of cognitive impairment and dementia. Cochrane Database Syst Rev. 2017;6(6):CD003804. https://doi.org/10.1002/14651858. cd003804.pub2 PMid:28617932

10. Hair JF, Black WC, Babin BJ, Anderson RE. Multivariate Data Analysis. $7^{\text {th }}$ ed. United States: Pearson Prentice Hall; 2010.

11. Sujit KS, Rajesh BK. Determinants of discretionary investments: Evidence from Indian food industry. SAGE Open. 2016;6(1):2158244016636429. https://doi. org/10.1177/2158244016636429

12. Chin WW. How to write up and report PLS analyses. In: Handbook of Partial Least Squares: Concepts, Methods and Applications. Berlin, Heidelberg: Springer-Verlag; 2010. https:// doi.org/10.1007/978-3-540-32827-8_29

13. Chin WW. The partial least squares approach to structural equation modeling. Mod Methods Bus Res. 1998;295(2):295-336.
14. Anderson RE, Hair JF, Black WC, Babin BJ. Multivariate Data Analysis. London, United Kingdom: Pearson Education; 2009.

15. Van Dijk JW, Venema M, Van Mechelen W, Stehouwer CD, Hartgens F, Van Loon LC. Effect of moderate-intensity exercise versus activities of daily living on 24-hour blood glucose homeostasis in male patients with Type 2 diabetes. Diabetes Care. 2013;36(11):3448-53. https://doi.org/10.2337/ dc12-2620

\section{PMid:24041682}

16. Iwai $\mathrm{K}$, Ushigome E, Yokota I, Majima S, Nakanishi N, Hashimoto $Y$, et al. Usefulness of exercise for home blood pressure control in people with diabetes: A study protocol for a crossover randomized controlled trial. Diabetes Metab Syndr Obes Targets Ther. 2020;13:4747-53. https://doi.org/10.2147/ dmso.s280117

PMid:33299337

17. Horgas AL, Wilms HU, Baltes MM. Daily life in very old age: Everyday activities as expression of successful living. Gerontologist. 1998;38(5):556-68.

18. Ramon-Jeronimo MA, Peral-Peral B, Arenas-Gaitan J. Elderly persons and internet use. Soc Sci Comput Rev. 2013;31(4):389403. https://doi.org/10.1177/0894439312473421

19. Bianchi $C$. Exploring how internet services can enhance elderly well-being. J Serv Mark. 2021;22(7):e15683.

20. Sancini A, Ricci S, Tomei F, Sacco C, Pacchiarotti A, Nardone N, et al. Work related stress and blood glucose levels. Ann Ig. 2017;29(2):123-33.

PMid:28244581

21. Benton D. The impact of increasing blood glucose on psychological functioning. Biol Psychol. 1990;30(1):13-9. PMid:2223932

22. Bando H, Muneta T, Bando M, Yonei Y. Effect of low carbohydrate diet on Type 2 diabetic patients and usefulness of M-value. Diabetes Res Open J. 2017;3(1):9-16. https://doi. org/10.46527/2582-5038.103

23. Garber MC. Exercise as a stress coping mechanism in a pharmacy student population. Am J Pharm Educ. 2017;81(3):50. PMid:28496270 